\title{
A bibliometric analysis of Wnt signaling pathway: from the top-100 cited articles to emerging trends
}

\author{
Jia-Qi Xu ${ }^{1,2 \#} \wedge$, Ning Tang ${ }^{1 \#}$, Ling-Feng Zhang ${ }^{2}$, Chen Tan ${ }^{2}$, Yang Su ${ }^{1}$, Daniel M. George ${ }^{3}$, Guang-Xu He ${ }^{1}$, \\ Tian-Long Huang ${ }^{\wedge} \wedge$
}

${ }^{1}$ Orthopaedic Department, The Second Xiangya Hospital of Central South University, Changsha, China; ${ }^{2}$ Royal Adelaide Hospital, Adelaide, SA, Australia; ${ }^{3}$ Xiangya School of Medicine, Central South University, Changsha, China

Contributions: (I) Conception and design: TL Huang, JQ Xu, N Tang; (II) Administrative support: None; (III) Provision of study materials or patients: None; (IV) Collection and assembly of data: LF Zhang, C Tan, Y Su; (V) Data analysis and interpretation: JQ Xu, N Tang; (VI) Manuscript writing: All authors; (VII) Final approval of manuscript: All authors.

\#These authors contributed equally to this work.

Correspondence to: Tian-Long Huang. Xiangya School of Medicine, Central South University, No. 139 Middle Renmin Road, Changsha 410011, China. Email: tianlong.huang@csu.edu.cn.

\begin{abstract}
Background: Wnt signaling pathway plays a vital role in the regulation of development. An increasing number of articles about Wnt pathway components have been published. By analyzing these studies' characteristics and qualities, we aim to reveal the current research focus and emerging trends in Wnt signaling.

Methods: The databases of Web of Science Core Collection, BIOSIS Citation Index, MEDLINE, etc. were utilized to identify articles on May 23rd, 2020. Wnt signaling pathway-related articles were identified, the 100 most cited articles and articles in the last decade were selected and calculated for citations without self-citation. The subsequent analysis included citation density (citations/article age), time-related flux, authorship, institution, journal, geographic distribution, and theme.

Results: These articles were published mainly from 2000 to 2009 (62\%). Citations per article ranged from 599 to 3,780 with a median number of 880 times. Most studies (66\%) came from the United States. Nusse Roel and Clevers Hans (15 and 13 papers) have contributed significantly to the field. The most highlighted study themes were cancer (15\%), embryo development (14\%), and cytoplasm signal transduction (11\%). From 2011 to 2020, interest in emerging subtopics, including osteogenesis, immune, apoptosis, autophagy, microRNA, and cancer stem cell, are rising.

Conclusions: Cancer, embryo development, stem cell, and signal transduction process still play a major role in the field. With multiple emerging subtopics and investigation on an integrated view of the Wnt signal network, the association of Wnt with diseases was further revealed.
\end{abstract}

Keywords: Bibliometric analysis; top-100 articles; cell signaling; Wnt; $\beta$-catenin; embryo development; cancer

Submitted Jan 12, 2021. Accepted for publication Apr 02, 2021.

doi: $10.21037 /$ atm-21-174

View this article at: http://dx.doi.org/10.21037/atm-21-174

^ ORCID: Jia-Qi Xu 0000-0002-4883-7358; Tian-Long Huang 0000-0001-9278-2350. 


\section{Introduction}

Nearly four decades after the discovery of the Wnt1 gene (1), which encodes the first member of the Wnt family, interest and insight in Wnt signaling pathways are still rapidly increasing. This family of secreted glycollipoproteins, along with various agonist and antagonist, weaves an intricate signal network and plays an important role in development, physiological processes, and disease $(2,3)$. So far, three Wnt signaling pathways are the focus of investigation, the canonical $\beta$-catenin pathway, planar cell polarity $(\mathrm{PCP})$ pathway, and the $\mathrm{Wnt} / \mathrm{Ca} 2+$ pathway (4). The $W n t / \beta$-catenin pathway has been well described in receptor signaling, cytoplasmic signal transduction, and nuclear transcription (5). Wnt genes are found in all animal genomes and are indispensable for embryo development (6). Besides, bone mass regulation (7), stem cell differentiation (8), degenerative disease (9), and carcinogenesis (10) are all closely correlated with Wnt signaling. With the link between disease and Wnt further revealed, therapeutic targets are also emerging (11). However, further research and analysis are required to understand the signal regulation process and therapeutic utilities fully. Hans Clevers and Roel Nusse (2012) have pointed out ten questions in the Wnt field (12), some of which are still worth investigating today.

Bibliometric analysis is a unique and efficient tool for analyzing the influence, characteristics, and trends of published articles on specific topics. It was used in many fields, including orthopedics $(13,14)$, thoracic surgery (15), radiography (16), and cancer (17). During the analyzing process, basic characteristics of identified manuscripts were first extracted. Then the quality and distribution of manuscripts were evaluated using statistical methods and analyzing tools. Citation analysis was one of its key methodologies. Citation number received by manuscripts is viewed as a marker for its importance and is reflected in the impact factor of journals. Generally, high-cited articles provided the basis for their field, and growing citation counts often mean emerging focuses $(18,19)$. Recently, a bibliometric analysis of signaling pathways is becoming increasingly popular $(20,21)$. While most bibliometric analyses look at the top 100 most cited articles in a research area, another method analyzes all the articles within the search range to obtain information. For example, the advancements and trends in Wnt signaling in liver diseases were quantitatively summarized by this mean (20). However, few bibliometric studies analyzed both the top- cited and most recent studies. And a comprehensive analysis of the overall Wnt field remains to be completed.

In this study, we combine the bibliometric analysis of the top 100 most cited articles and all articles within the last ten years in the Wnt field. While analyzing the history and critical advances in the development of Wnt, we aim to elucidate the growing trends and future direction of this vital cellular signaling pathway.

\section{Methods}

\section{Search strategy and criteria}

Articles were identified by searching in the ISI Web of Science database (Thomson Reuters, New York, the United States). We selected WOS Core Collection, BIOSIS Citation Index, KCI-Korean Journal Database, MEDLINE, Russian Science Citation Index, and SciELO Citation Index in WOS to retrieve all articles related to Wnt. The search terms used were the following: "wnt" OR "wingless" OR "wingless-type" OR "int-1". The search was conducted in May 23rd, 2020 and yielded a total of 61,469 results; both original articles and review articles were included. After reviewing the title and abstract, the 275 topcited articles cited were included to reduce the number of articles necessitating subsequent screening, which resulted in 61,194 articles excluded from analysis. Two independent investigators read and analyzed the whole content of the 275 included articles at the same time to enhance the screening sensitivity. Inclusion criteria: (I) basic study and animal study in molecular biology, cell biology, genetics, developmental biology, which consider Wnt as the research core; (II) the clinical studies of Wnt related disease; (III) reviews on particular Wnt related field or comprehensive Wnt signaling review. Exclusion criteria: (I) content not related to Wnt; (II) Wnt which is not the central focus of the topic. The disagreement between the two reviewers was discussed to reach an agreement. After the screening, 144 articles failed to meet the inclusion criteria, and 131 articles were qualified for analysis. These articles were ranked in descending order of citations without self-citation, and the top 100 most cited articles were included.

Meanwhile, we analyzed all articles within the last ten years in the Wnt field. For research's consistency and an accurate prediction of emerging trends, we used the same Database portfolio and search terms as above. By limiting the publication date to the last decade (2011 to 2020), we retrieved 41,337 articles. Those articles were subsequently 


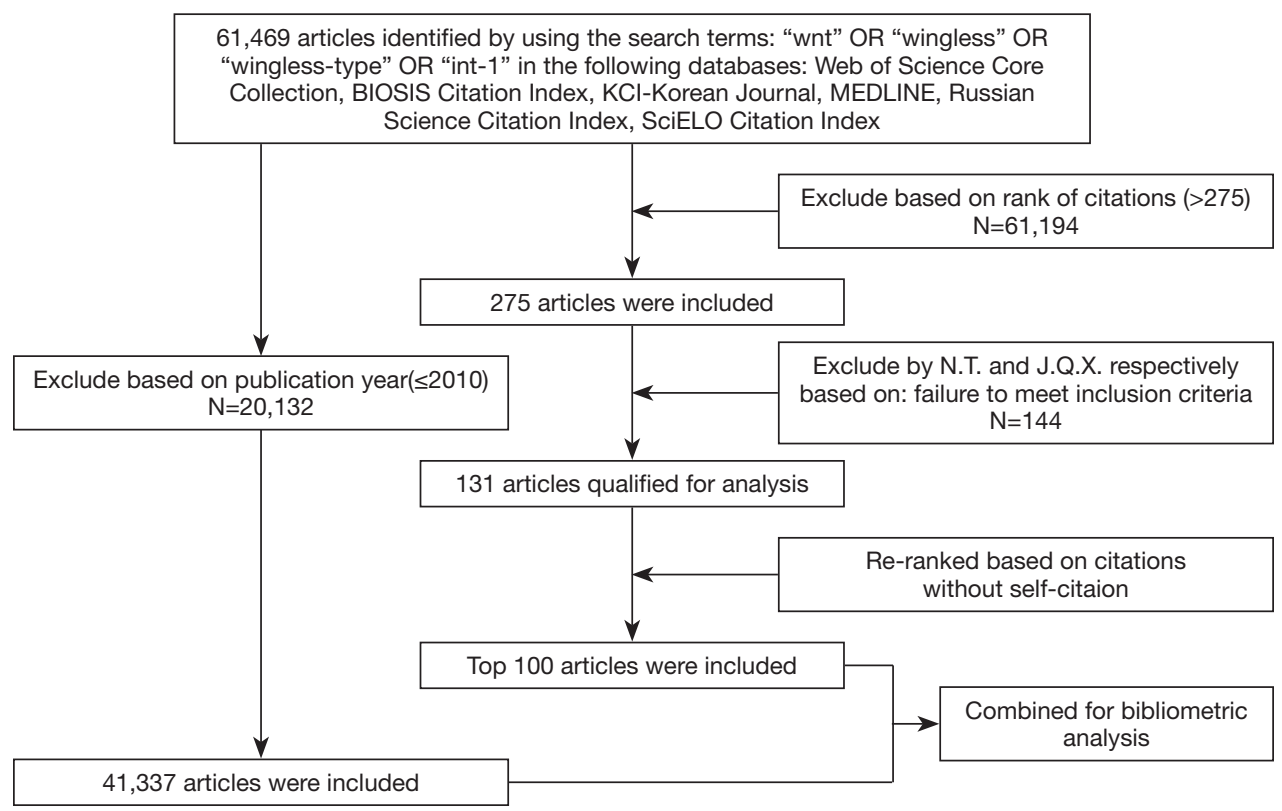

Figure 1 Flowchart illustrating the process of allocation of articles. The detailed process of screening and enrollment.

analyzed utilizing Vosviewer. Finally, the aforementioned two strategies were combined for further analysis (Figure 1).

\section{Data extraction}

Two independent, well-trained investigators reviewed the top 100 articles. The following information was listed for all 100 articles: the journal name, author, year of publication, geographic origin, research institution and department, keywords, abstract, research theme, the total number of citations. The geographic origin, research institution and department were determined based on the affiliation of the corresponding author. When there are multiple affiliations of corresponding author, the institution of first author was utilized. We carefully reviewed all articles and used two or three words to summarize and categorize each article's themes adequately. Then we acquired self-citation numbers and citations in the last five years while WOS. Citations without self-citation were calculated by subtracting the selfcitation number from the total number of citations. Citation density was equal to "citations without self-citation/ article age". For the latter retrieved 41337 manuscripts, information on the titles, keywords, author, institution, country, abstract, and references was all stored.

\section{Statistical analysis}

The Kolmogorov-Smirnov test was used to test the distribution of individual variables for normality. Normally distributed data are presented as mean \pm standard deviation. Comparison between means was performed using one-way analysis of variance (ANOVA), and posthoc testing was undertaken when necessary. Timedependent trends were tested using the Mann-Kendall trend test. Correlation between variables was performed using the Spearman rank or Pearson tests. A $\mathrm{P}<0.05$ was considered to be statistically significant. The analysis was performed using Graphpad Prism 8, R 4.0.2, and IBM SPSS Statistics 22.0.

The bibliometric software Vosviewer_1.6.15 was utilized for this study. "Overlay visualization" was adopted to identify important keywords and give relative impact to each keyword based on its calculated value. The keywords could be considered as substitutions of scientific ideas and be used to construct a co-occurrence network. A restriction with a minimum number of occurrences of a keyword was set (scale factor $=100$ ). The keywords with the highest occurrences in the network have the larger circle, representing the scientific ideas over the years. Moreover, a blue-yellow gradient was utilized to show how the author's keywords changed over time. 
Table 1 Top 10 articles with largest citation density

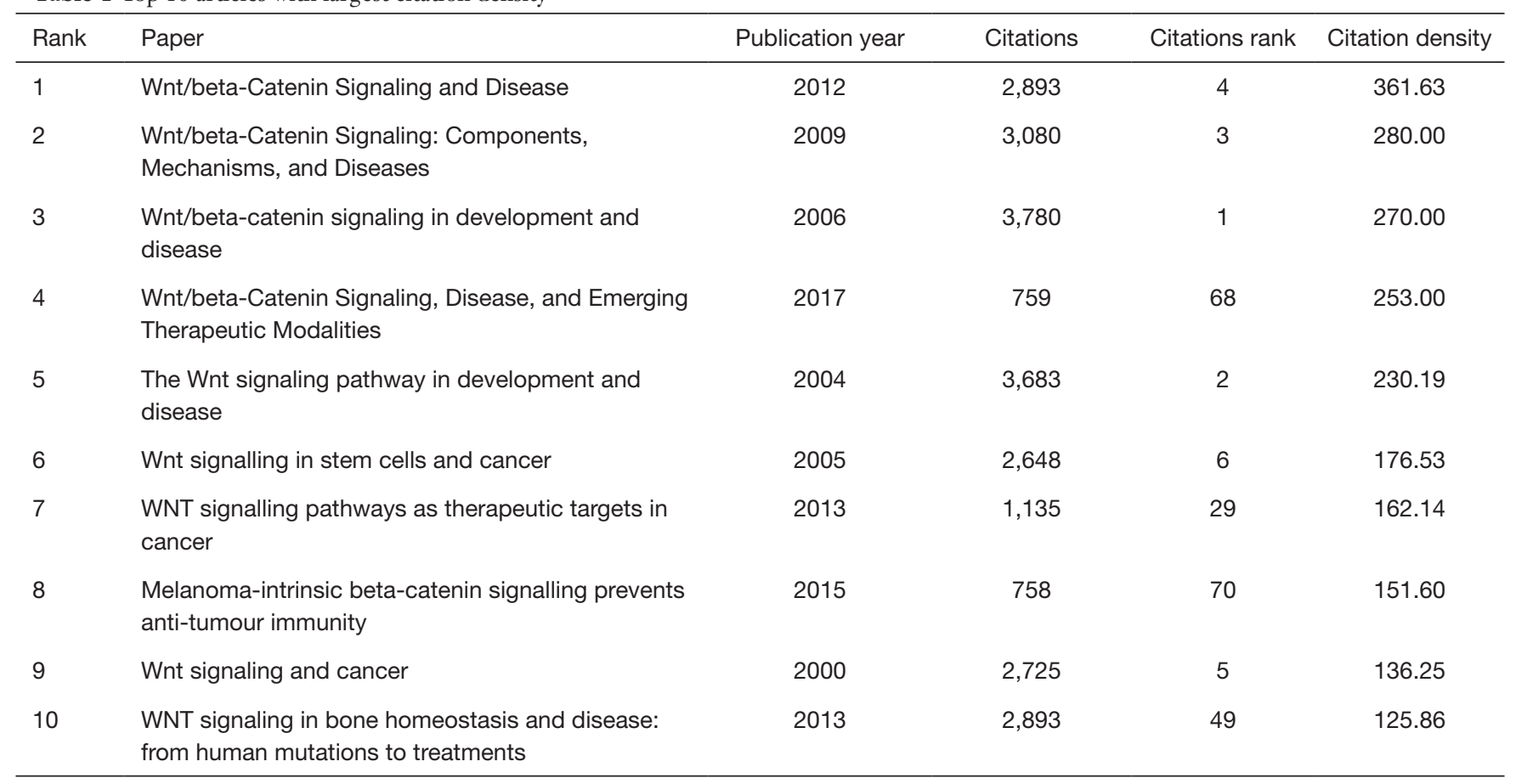

\section{Results}

\section{Top articles}

The 100 most cited articles on Wnt research were listed in Table S1 based on citations without self-citation. For convenience, "citations" were used instead to refer to "citations without self-citation" in our later statements. Original articles comprised $70 \%$, and review articles comprised $30 \%$ of the papers. The number of citations ranged from 599 to 3,780 , with a median number of 880 . Of the top 50 articles, 33 were still in the first half when ranked by citations in the last five years.

The top 10 articles with the largest citation density were listed in Table 1. Nine of them were review articles. They were all published after 2000, with a mean citation number of 2,435 and a mean citation density of 214.72 . Four reviews were published after 2010, and the only original article by Spranger et al. was published in 2015.

\section{Time analysis}

A majority of articles were published between 2000 to 2009 (62\%), articles published since 2010 only accounted for 9\% (Figure 2A). The Mann-Kendall trend test showed no trend between the citations and the time $(\mathrm{P}=0.3421)$ but an increasing trend between the citation density and the time $(\mathrm{P}=5.32 \mathrm{E}-14)$ (Figure 2B). The Spearman rank revealed a positive correlation between time and citation density (Spearman's $=0.639, \mathrm{P}<0.01$ ).

\section{Country and institutional analysis}

The country distribution of these articles is demonstrated on the diagram (Figure 2C). They were distributed in 9 countries, led by the United States $(n=66)$, followed by Germany ( $n=14)$ and the Netherlands $(n=9)$. Almost all of the articles came from two regions: the United States and Western Europe. Only six articles scatted in other areas: Japan, Canada, and Brazil.

Globally, a total of 48 institutions published articles independently or cooperatively. Among them, 20 institutions that published 2 or more articles were listed (Figure 2D). The top 3 institutions were HHMI (The Howard Hughes Medical Institute) ( $n=14)$, Harvard University ( $\mathrm{n}=9)$, and Utrecht University $(\mathrm{n}=8)$.

\section{Fournal and author analysis}

The top 10 journals in which all articles were published are listed in Table 2. Moreover, Thirty-two journals in which 


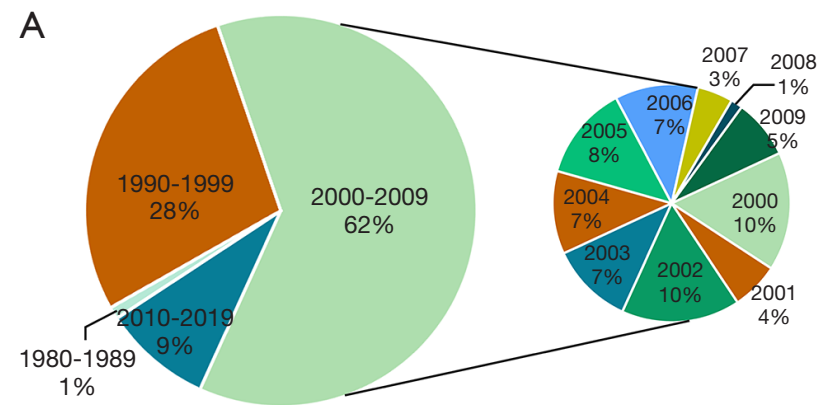

B
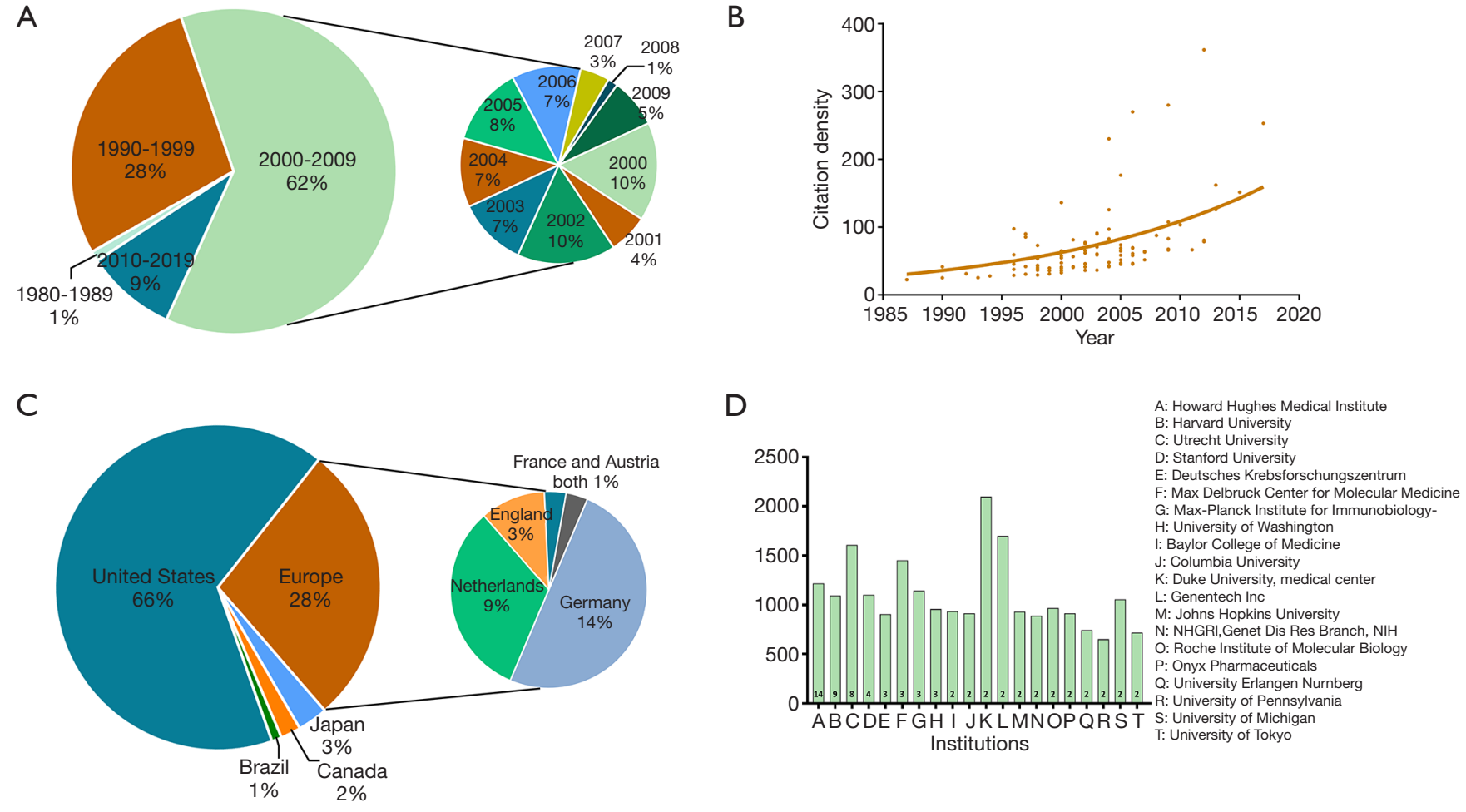

Figure 2 Time and distribution analysis of 100 top-cited articles in Wnt. (A) A majority of articles were published in 2000-2009 (62\%, $\mathrm{n}=62$ ). (B) Time-dependent citation density trend. Mann-Kendall trend test showed an increasing trend between the citation density and the time (P=5.32E-14). (C) Geographical distribution of all articles. The figure showed that almost all of the articles came from two regions: United States and Western Europe. Only 6 articles scatted in other areas: Japan, Canada and Brazil. (D) Mean citation per article and article numbers based on institution. Howard Hughes Medical Institute was the institute with most articles, followed by Harvard University, Utrecht University and Stanford University.

all articles were published are listed in Table S2. Twenty articles were published in Nature, followed by Cell $(\mathrm{n}=18)$, Science $(\mathrm{n}=7)$, Development $(\mathrm{n}=7)$, and Dev Cell $(\mathrm{n}=6)$. Their impact factors ranged from 2.126 (Mech Dev) to 74.699 (N Engl 7 Med) with a median of 11.333 .

Authors with three or more articles and their basic information are listed in Table 3. Nusse Roel, from Stanford University, founder of Wnt signaling, had 15 authorships. The total citations of his selected articles were 22086. Clevers Hans, from Utrecht University, had 13 authorships, mainly in the study of transcription factor TCF/LEF family and gastrointestinal tumor. The total citations of his selected articles were 19,125.

\section{Trends in research subtopics}

The top 100 most cited articles focused principally on the following themes: cancer $(n=28)$, embryo development $(n=25)$, cytoplasm signal transduction $(n=20)$, receptor and co-receptor $(\mathrm{n}=19)$, antagonist $(\mathrm{n}=17)$, stem cells $(n=13)$, osteogenesis $(n=12)$, nuclear function $(n=12)$, signal integration $(\mathrm{n}=6)$, agonist $(\mathrm{n}=6)$, hair follicle morphogenesis $(\mathrm{n}=5)$ and OPPG (osteoporosis-pseudoglioma syndrome) $(n=4)$ (Figure 3). Though a majority of them focused on the canonical $W n t / \beta$-catenin pathway $(n=87)$, there were articles specializing in PCP pathway $(\mathrm{n}=8)$ and $\mathrm{Wnt} / \mathrm{Ca}^{2+}$ pathway $(n=5)$. One-way ANOVA revealed no significant difference in citations per article among various themes ( $\mathrm{P}=0.388)$.

Since $91 \%$ of the top 100 articles were published prior to 2010, to demonstrate the research trends in the Wnt field more directly, we aditionally conducted a keywords co-occurrence analysis on articles over the last decade. Nodes and links made up the network figure. In the overlay visualization (Figure $4 A$ ), links between keyword nodes represented their co-occurrence. The size of a node 
Table 2 Top 10 journal in which the top-cited 100 articles were published

\begin{tabular}{|c|c|c|c|c|}
\hline Journal & Country & IF (2019) & Number of articles & Total citations \\
\hline Cell & United States & 38.637 & 18 & 22,697 \\
\hline Science & United States & 41.845 & 7 & 8,189 \\
\hline Development & United Kingdom & 5.611 & 7 & 4,959 \\
\hline Genes \& Development (Genes Dev) & United States & 9.527 & 4 & 6,328 \\
\hline Nature Medicine (Nat Med) & United States & 36.130 & 3 & 3,268 \\
\hline Nature Genetics (Nat Genet) & United States & 27.603 & 3 & 2,217 \\
\hline The EMBO journal (EMBO J) & United States & 9.889 & 3 & 3,561 \\
\hline
\end{tabular}

depends on its weight, which is set as the total strength of the links of a keyword node. Distance between two nodes in the visualization approximately indicates the relatedness of the keywords. In general, the closer the two nodes are located to each other, the stronger their relatedness is in the co-occurrence network. Furthermore, each node is colored based on the average publication year they occurrence with a blue to yellow gradient.

In the cluster visualization (Figure $4 B$ ), the more items in the neighborhood of a node and the higher the weights of the neighboring items, the closer in color the point is to yellow; the fewer items in the neighborhood of a node and the lower the weights of the neighboring terms, the closer in color the point is to blue.

Keywords were clustered into three main groups and four clusters, with Wnt and $\beta$-catenin at the convergence point. Group 1 (cluster 2) on the top included hedgehog/ notch signal. Group 2 (cluster 1 and 4 ) in the lower right mainly included multiple cancer types (colorectal cancer, hepatocellular carcinoma, pancreatic cancer, glioma, gastric cancer, cervical cancer, osteosarcoma, bladder cancer and nasopharyngeal carcinoma), tumor progression, development, stem cells, hair follicle and model organisms such as zebrafish, drosophila and xenopus. Group 3 (cluster 3) in the lower-left mainly focused on two themes. One is the development and disease of bones, including osteogenesis, osteoporosis, osteoarthritis, osteoblast, and sclerostin. The other is aging, neural, and degenerative disease. Canonical Wnt/ $\beta$-catenin pathway plays a central role in the field. Along with top keywords ranked by total link strength and average publication year listed in
Tables S3,S4, we revealed emerging research subtopics including osteogenesis, apoptosis, autophagy, microRNA, and cancer stem cells. Also, tumor metastasis, proliferation, migration, and invasion seem to be essential research directions with many yellow nodes.

\section{Discussion}

To our knowledge, this is the first bibliometric analysis of the overall Wnt signaling field. Numerous significant findings can be drawn from this analysis.

\section{Bibliometric findings}

The maximum number of citations reached 3,780 , which was a review in 2006 by Clevers Hans (2). The comprehensive review summarized advances on canonical $\mathrm{Wnt} / \beta$-catenin signal in detail, from the origin of $\mathrm{Wnt}$, embryo development, exquisite signal component to the cause of hereditary diseases and cancer. With 1,224 citations in the last five years, it is still one of the most fundamental articles on Wnt. The attitude toward citing review articles over original research was evident here (16). Thirty of the top 100 articles were reviews, and they were continually cited nowadays for more comprehensive and authoritative information.

The majority of the top-cited articles were published from 2000-2009, and only 9 articles published since 2010 made the top 100 . This could be explained by a common bias in bibliometric analysis, which is that the latest published articles have not had enough time to be 
Table 3 Author with three or more articles

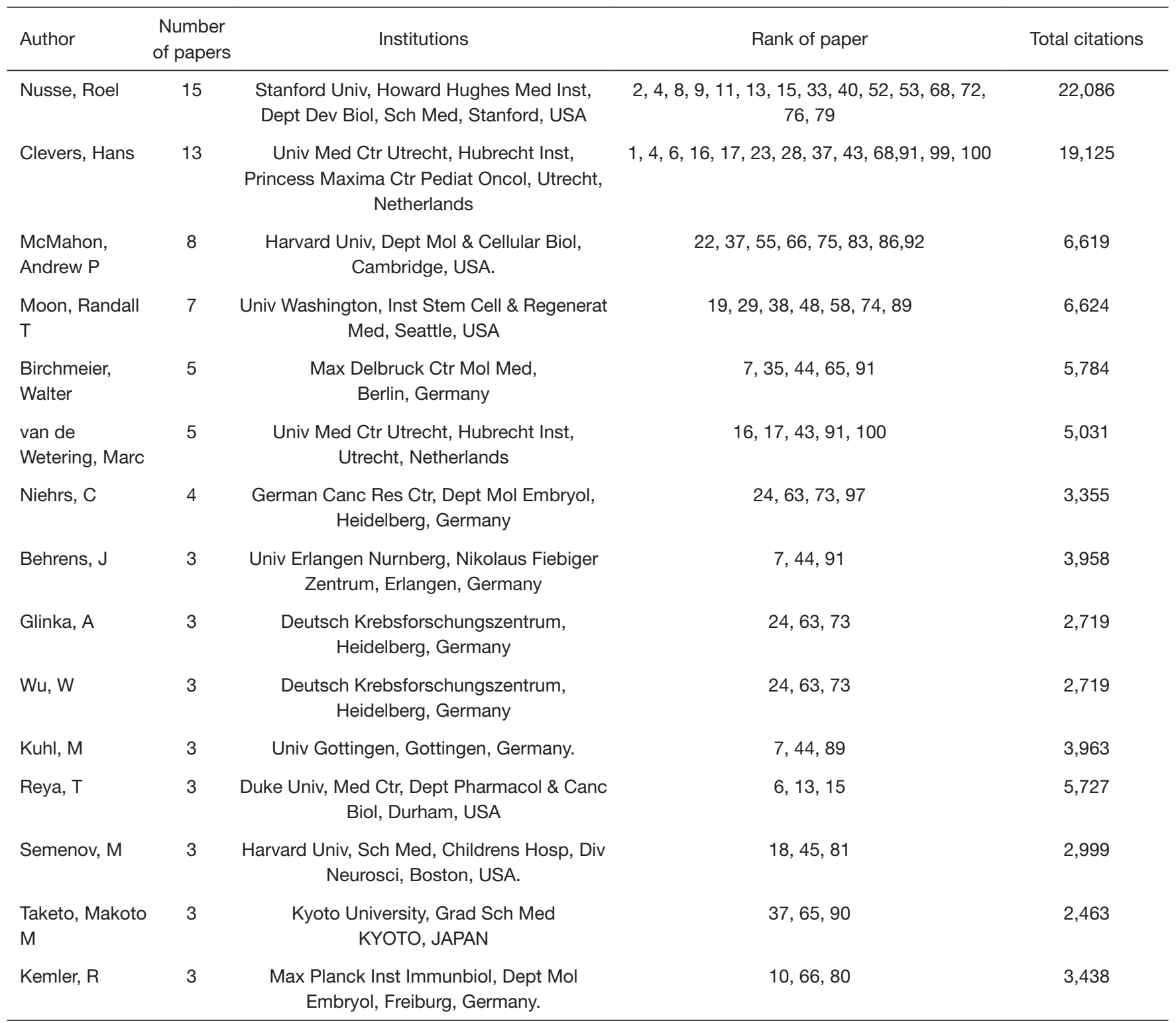

cited. Therefore, the citation density of each article was calculated to help assess the importance of articles. MannKendall trend test showed an increasing trend between the citation density and the time with significant difference $(\mathrm{P}=5.32 \mathrm{E}-14)$, indicating the increasing attention been paid to Wnt signaling research.

The articles' regional distribution demonstrated that most of the articles originated from the United States and Western Europe. There are several reasons for this phenomenon: (I) Wnt research originated in the United States, since Roel Nusse discovered oncogene int-1 in 1982 and Drosophila wingless gene in 1987 (1,22). His work in developmental biology, cancer, and stem cell research had promoted the deep development of Wnt signaling. Hence, they started to study it earlier and more thoroughly; (II) scientists such as Clevers Hans from the Netherlands has been studying the transcription factors TCF-1 and LEF-1 since the 1990s (23). Two original articles in the top 10 were from Germany in 1996 and 1997. Groups from them continued to investigate Wnt with cancer and embryo development. (III) Countries, including the United States, Netherlands, and Germany, have a developed economy for 


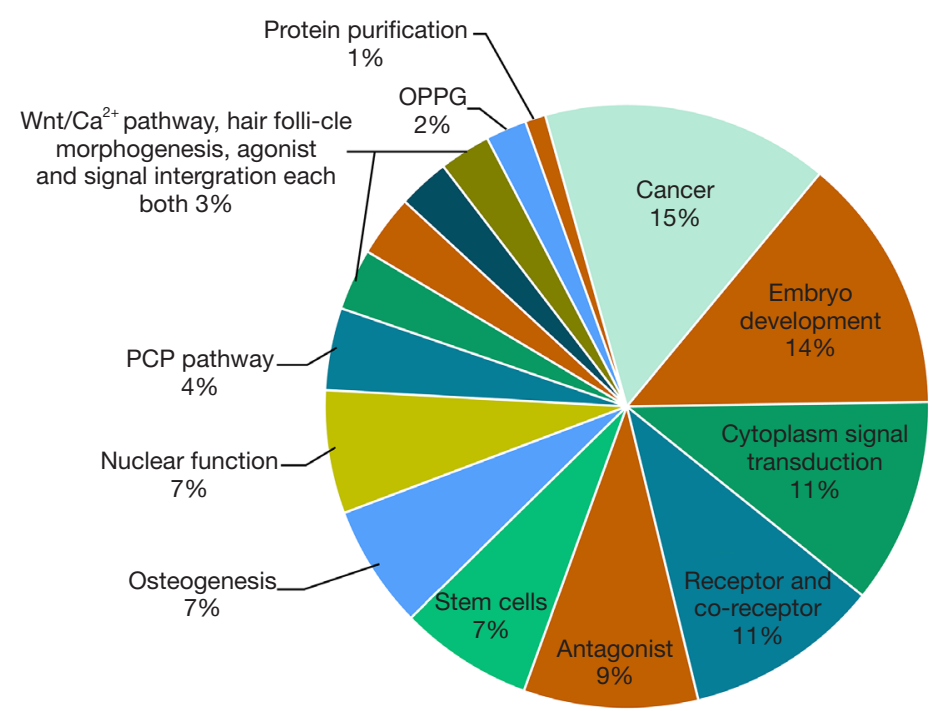

Figure 3 Theme distribution of 100 top-cited articles in Wnt. Cancer $(n=28)$, embryo development $(n=25)$ and cytoplasm signal transduction $(\mathrm{n}=20)$ were the top 3 most common themes published. OPPG, osteoporosis-pseudoglioma syndrome; PCP, planar cell polarity.

basic medical research; there is a weak correlation between the gross domestic product (GDP) per capita and their research achievements (24). The HHMI (Howard Hughes Medical Institute) was the institution with the most articles $(\mathrm{n}=14)$. It was an American non-profit Medical research Institute that collaborated with universities including Stanford University, University of Washington, and the Johns Hopkins University.

Nature, Cell, Science, Development, and Dev cell covered 58 articles in the top 100, which again emphasized the importance of Wnt in developmental biology, cancer therapy, and stem cell biology. The theme distribution of the most cited articles was examined Figure 3. A keyword co-occurrence analysis was then performed utilizing Vosiviewer to obtain the research trends in the last decade. Relevant landmark manuscripts are discussed in combination with Figure 4, which further indicated trends in multiple cancer and stem cell research.

\section{Research focuses in Wnt}

"Wnt/beta-Catenin Signaling and Disease" published in 2012 by Clevers Hans and Roel Nusse was the most cited article in the last five years (1,807 times), and is also the article with the largest citation density (361.63) (12). They provided an update of the $\mathrm{Wnt} / \beta$-catenin signal transduction cascade and discussed the latest research on how the pathway contributed to diseases. Intestinal cancer, hepatocellular carcinoma, melanoma, sebaceous skin tumors, type II diabetes as well as bone disease were mentioned. Furthermore, the review summarized Wnt signal pathway target modulators and raised unsolved questions in the field. They further updated a comprehensive review in 2017 (11). Emerging topics, including the role of $\mathrm{Wnt}$ as growth factors, controlling of stem cell biology, organoids growing, and Wnt therapeutic actions in the clinic, were discussed.

Colorectal cancer was the most studied cancer type $(25,26)$ (Figure 4A). Aberrant cytoplasmic APC/Axin destruction complex and epigenetic loss of secreted frizzledrelated protein (SFRP) function were regarded as the main mechanisms. Mutated APC activated Wnt pathway and formed a constitutively active $\beta$-catenin/Tcf4 complex in the intestinal epithelial cell, resulting in tumors' progression $(27,28)$. MicroRNA also served as important links between function loss of APC and the absence of cancer suppressor genes in colorectal cancer (29).

In embryo development and stem cell biology, modulation of Wnt signaling was essential for the proliferation and differentiation of human pluripotent stem cells (hPSCs), muscle stem cells, hematopoietic stem cells, and epidermal stem cells (8,30-32). Newly developed surrogate $\mathrm{Wnt}$ agonists which are similar to Wnt were found to elicit $\beta$-catenin signaling responses, 
A
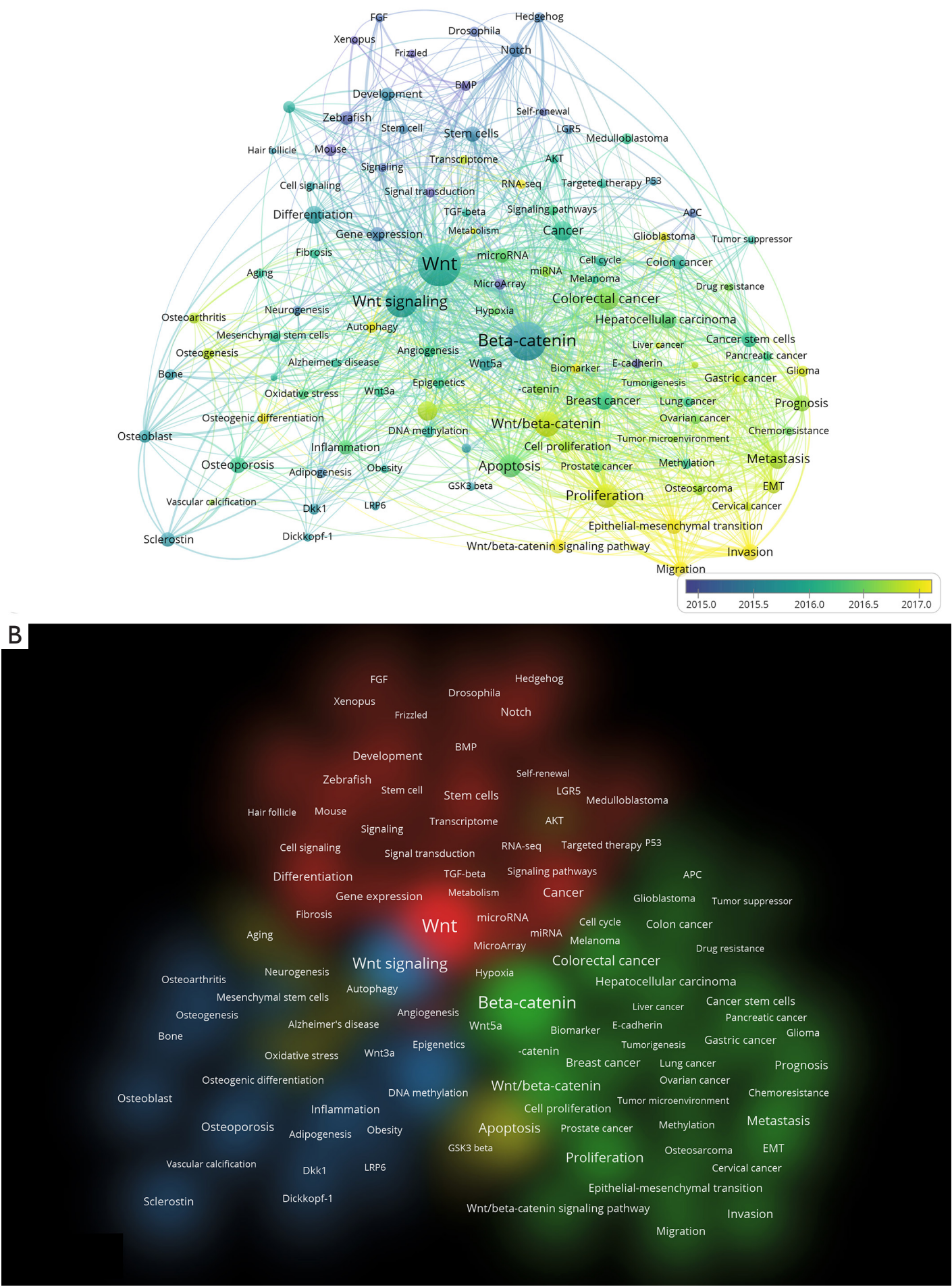

Figure 4 Network plot of keywords in Wnt research over the past decade. (A) Overlay visualization, (B) cluster visualization. Of the 35,098 terms, 109 terms have occurred at least 100 times. For each of the terms, a relevance score was determined and used to select the $85 \%$ most relevant terms. The size of the circles in Figure represents the occurrences of terms. 
resulting in enhancement of the osteogenic lineage commitment of mesenchymal stem cells (MSCs). The agonists further support the growth of primary human organoid cultures, regulate metabolic liver zonation and promote hepatocyte proliferation (33). As for bone MSCs, Wnt activator upregulated their osteogenic differentiation and osteogenesis (34). The crucial role of Wnt signaling in bone metabolism and skeletal disorders have facilitated the clinical understanding of osteoporosis, osteoarthritis, rheumatoid arthritis, and neoplasia (35). Balance and interaction between Wnt and R-Spondin (RSpo) ligands can potentially control tissue regeneration (36). Stimulation with Wnt and Activin could also induce a unique organizer.

Moreover, human stem cell colonies treated with these proteins induced a secondary axis while inducing a neural fate when grafted into chick embryos (37). Adult stem cell markers Lgr4 and Lgr5 were associate with the Frizzled/ Lrp Wnt receptor complex and widely studied in intestinal epithelium homeostasis. A recent study proved the function of $\operatorname{Lgr} 5$ as a glioma stem cell marker on promoting epithelial-mesenchymal transition (EMT) via Wnt/ $\beta$-catenin pathway, which resulted in the poor prognosis of the gliomas (38).

In efforts to better understand the process from Wnt lipid modification to nuclear target gene expression, quantities of cytoplasmic components, receptor, coreceptor, antagonist, and agonist were more thoroughly acknowledged. Antagonist dickkopf 1 (DKK1) was found to inhibit osteoblast differentiation and cause lytic bone lesions in patients with multiple myeloma. It was verified by the only case-control study in the top 100, published in the NEngl 7 Med (39).

Though most of the research was conducted in cells or model organisms, several clinical studies bring the Wnt signaling pathway into clinical therapeutic applications. An antibody Romosozumab targeting the SOST gene, a negative regulator of Wnt in bone tissue, has made progress in postmenopausal women with osteoporosis (40). Another clinical trial of the Porcupine inhibitor LGK974 for cancer therapy was also ongoing. (https://clinicaltrials.gov/ct2/ show/NCT01351103)

\section{Emerging trends in Wnt}

Besides the extensively studied themes in Figure 3, novel directions showed broad prospects. The only original article in Table 1 was about anti-tumor immunity with a citation density of 156.60 (41). Through experiments on melanoma, the authors revealed a correlation between $\mathrm{Wnt} / \beta$-catenin signaling pathway and the absence of a T-cell gene expression signature. They further demonstrated that tumor-intrinsic active $\beta$-catenin signaling results in T-cell exclusion and resistance to anti-PD-L1/anti-CTLA-4 monoclonal antibody therapy.

Yellow nodes in Figure $4 A$ show various themes in the last decade. Upregulated oncogenic lncRNA MALAT1 in tongue squamous cell carcinoma could inhibit cell apoptosis by activating $\mathrm{Wnt} /$ beta-catenin signaling pathway, which induced cell migration, invasion, and EMT (42). In chronic lymphocytic leukemia cells, Circular RNA circ-CBFB was also found to inhibit apoptosis by activating Wnt signaling. They both contributed to the progression of cancer (43). Therefore, novel agents targeting Wnt signaling were studied to inhibit cancer cell growth effectively $(44,45)$. Similarly, when $\mathrm{Wnt} / \mathrm{b}$-catenin signaling pathway was suppressed in nerve cells, the antiapoptotic and neuroprotective effects of Simvastatin were significantly reduced (46).

Association between non-coding single-stranded RNA molecules microRNA and Wnt were widely investigated recently, especially their role in cancer cell proliferation, migration, and invasion. For instance, microRNA-27a was found to promote cancer progression (47), while microRNA-16, 100, 506 inhibited cell proliferation and metastasis (48-50). In liver fibrosis and osteoarthritis, microRNA could also influence disease progress through modulating the pathway $(51,52)$.

Autophagy, a self-digestion process to promote cell survival in response to external stresses, has a complicated reciprocal relationship with the Wnt signaling. In neural ischemia and hypoxia, autophagy activation downregulated the downstream proteins of the Wnt/beta-catenin signaling (53). Recently, the beta-catenin deficiency was first reported to induce autophagy in multiple myeloma cells (54). Most studies verified induced autophagy and apoptosis via suppressing the pathway $(54,55)$. In human non-small cell lung cancer, tumor suppressor candidate 3 (TUSC3) was found to promote autophagy and Wnt signaling simultaneously (56).

Wnt also functioned in cancer stem cells (CSCs). Self-renewal capability and accumulating mutations of tissue stem cells were thought to initiate tumor cellular transformation. This population of tumor cells continuously fuel tumor growth, self-renewal, and differentiation, which was termed CSCs (57). Mutations in CSC resulted in constitutively upregulated Wnt signaling, especially in intestinal stem cells. Multiple pieces of research have 
demonstrated the link between CSC properties and aberrantly activated Wnt (58).

Though most articles focused on canonical Wnt/ $\beta$-catenin pathway, the function and mechanism of $\beta$-catenin-independent Wnt pathways have been investigated. Initially, an overlap between Vertebrate Noncanonical Wnt Signaling and the Drosophila PCP Pathway was found (59). In establishing planar cell polarity and the control of polarized cell migration, Wnt/PCP pathway initiated with a Wnt-Frizzled interaction, followed by downstream components include Dishevelled (Dvl), small Rho GTPases, and Jnk (4). From studies on Wnt5A and rat Frizzled-2, Wnt/Ca ${ }^{2+}$ pathway was also revealed gradually. Activation of the $\mathrm{Wnt} / \mathrm{Ca}^{2+}$ pathway resulted in $\beta$-catenin independent activation of $\mathrm{Ca}^{2+}$-calmodulindependent protein kinase II (CamKII) and protein kinase $\mathrm{C}$ (PKC) (60). Along with the pathway activated by receptor tyrosine kinase (RTK) Ror2 and Ryk, a more integrated view of Wnt signaling pathway was depicted. Ror2 can inhibit $\beta$-catenin/TCF signaling and activate Jnk, while $\mathrm{Wnt} / \mathrm{Ca}^{2+}$ was thought to be overlapped with Wnt/PCP (4). Furthermore, considering emerging research subtopics on Wnt with cell signaling such as NF-Kb, mTOR, and Hedgehog/Notch (61-63), it would be more innovative in the study of signal networks rather than a linear pathway.

\section{Limitations}

This analysis yielded some valuable information, but there were some limitations: (I) Given the breadth of the Wnt field, some small sub-topics have not been addressed and reflected; (II) newly published articles have not had enough time to be cited; (III) our analysis focused on Englishlanguage manuscripts, data from non-English-language sources was omitted. (IV) Except for the quality of articles, citation numbers can be influenced by factors including obliteration by incorporation (64), a tendency not to cite competitors or contradictory results, an attitude toward citing high-IF core journals and citing review articles over original research, in addition to national or language preferences (16). Of note, the use of "citations without selfcitation" reduced the error caused by self-citation. Cooccurrence analysis of articles in the last decade overcame bias towards historical articles.

\section{Conclusions}

This article highlights the top 100 cited articles and analyzes the latest articles in the last decade in the Wnt field, including their date and area distribution, authorship, journals, research themes, and keywords. Our work provides a comprehensive list of the landmark publications in Wnt signaling and recognizes contributions made by authors and institutions. Furthermore, we summarized the emerging trends in Wnt signaling. Cancer, embryo development, stem cell, and signal transduction processes are still central topics in the field. Meanwhile, research on osteogenesis, immune, apoptosis, autophagy, microRNA, and cancer stem cell are on the rise. Given the increasing burden of tumors, metabolic diseases, and degenerative disease, focus on $\mathrm{Wnt}$ will continue to grow. Investigation on an integrated view of the Wnt signal network will eventually lead to more clinical therapeutic modalities.

\section{Acknowledgments}

Funding: This work was supported by Hunan Provincial Innovation Foundation for Postgraduate (No.2020zzts885), the Innovation and Entrepreneurship Training Program for College Student (No. S2020105330605), Hunan province Funds for Distinguished Young youth: (grant number 2018JJ1046), and Youth program of national natural science foundation of China (grant number 81802207).

\section{Footnote}

Data Sharing Statement: Available at http://dx.doi. org/10.21037/atm-21-174

Peer Review File: Available at http://dx.doi.org/10.21037/ atm-21-174

Conflicts of Interest: All authors have completed the ICMJE uniform disclosure form (available at http://dx.doi. org/10.21037/atm-21-174). The authors have no conflicts of interest to declare.

Ethical Statement: The authors are accountable for all aspects of the work in ensuring that questions related to the accuracy or integrity of any part of the work are appropriately investigated and resolved.

Open Access Statement: This is an Open Access article distributed in accordance with the Creative Commons Attribution-NonCommercial-NoDerivs 4.0 International License (CC BY-NC-ND 4.0), which permits the non- 
commercial replication and distribution of the article with the strict proviso that no changes or edits are made and the original work is properly cited (including links to both the formal publication through the relevant DOI and the license). See: https://creativecommons.org/licenses/by-nc-nd/4.0/.

\section{References}

1. Nusse R, Varmus HE. Many tumors induced by the mouse mammary tumor virus contain a provirus integrated in the same region of the host genome. Cell 1982;31:99-109.

2. Clevers $\mathrm{H}$. Wnt/beta-catenin signaling in development and disease. Cell 2006;127:469-80.

3. Logan CY, Nusse R. The Wnt signaling pathway in development and disease. Annu Rev Cell Dev Biol 2004;20:781-810.

4. van Amerongen R, Nusse R. Towards an integrated view of Wnt signaling in development. Development 2009;136:3205-14.

5. MacDonald BT, Tamai K, He X. Wnt/beta-Catenin Signaling: Components, Mechanisms, and Diseases. Dev Cell 2009;17:9-26.

6. Yamaguchi TP, Bradley A, McMahon AP, et al. A Wnt5a pathway underlies outgrowth of multiple structures in the vertebrate embryo. Development 1999;126:1211-23.

7. Krishnan V, Bryant HU, MacDougald OA. Regulation of bone mass by Wnt signaling. J Clin Invest 2006;116:1202-9.

8. Lian X, Hsiao C, Wilson G, et al. Robust cardiomyocyte differentiation from human pluripotent stem cells via temporal modulation of canonical Wnt signaling. Proc Natl Acad Sci U S A 2012;109:E1848-57.

9. Cisternas P, Zolezzi JM, Martinez M, et al. Wnt-induced activation of glucose metabolism mediates the in vivo neuroprotective roles of Wnt signaling in Alzheimer disease. J Neurochem 2019;149:54-72.

10. Peifer M, Polakis P. Cancer - Wnt signaling in oncogenesis and embryogenesis - a look outside the nucleus. Science 2000;287:1606-9.

11. Nusse R, Clevers H. Wnt/beta-Catenin Signaling, Disease, and Emerging Therapeutic Modalities. Cell 2017;169:985-99.

12. Clevers H, Nusse R. Wnt/beta-Catenin Signaling and Disease. Cell 2012;149:1192-205.

13. Zhang W, Tang N, Li X, et al. The top 100 most cited articles on total hip arthroplasty: a bibliometric analysis. J Orthop Surg Res 2019;14:412.

14. Lum ZC, Pereira GC, Giordani M, et al. Top 100 most cited articles in orthopaedic surgery: An update. J Orthop 2020;19:132-7.

15. Ding H, Song X, Chen L, et al. The 100 most-cited papers in general thoracic surgery: A bibliography analysis. Int J Surg 2018;53:230-8.

16. Kim HJ, Yoon DY, Kim ES, et al. The 100 mostcited articles in neuroimaging: A bibliometric analysis. Neuroimage 2016;139:149-56.

17. Zhang Y, Quan L, Du L. The 100 top-cited studies in cancer immunotherapy. Artif Cells Nanomed Biotechnol 2019;47:2282-92.

18. Kulkarni AV, Busse JW, Shams I. Characteristics associated with citation rate of the medical literature. PLoS One 2007;2:e403.

19. Moed HF. New developments in the use of citation analysis in research evaluation. Arch Immunol Ther Exp (Warsz) 2009;57:13-8.

20. Jiang G, Huang C-K, Zhang $X$, et al. Wnt signaling in liver disease: emerging trends from a bibliometric perspective. PeerJ 2019;7:e7073.

21. Paunkov A, Chartoumpekis DV, Ziros PG, et al. A Bibliometric Review of the Keap1/Nrf2 Pathway and its Related Antioxidant Compounds. Antioxidants (Basel) 2019;8:353.

22. Rijsewijk F, Schuermann M, Wagenaar E, et al. The Drosophila homolog of the mouse mammary oncogene int-1 is identical to the segment polarity gene wingless. Cell 1987;50:649-57.

23. Oosterwegel $M$, van de Wetering $M$, Timmerman J, et al. Differential expression of the HMG box factors TCF-1 and LEF-1 during murine embryogenesis. Development 1993;118:439-48.

24. Tao T, Zhao X, Lou J, et al. The top cited clinical research articles on sepsis: a bibliometric analysis. Crit Care 2012;16:R110.

25. van de Wetering $M$, Sancho E, Verweij C, et al. The beta-catenin/TCF-4 complex imposes a crypt progenitor phenotype on colorectal cancer cells. Cell 2002;111:241-50.

26. Vermeulen L, Melo FDSE, van der Heijden M, et al. Wnt activity defines colon cancer stem cells and is regulated by the microenvironment. Nat Cell Biol 2010;12:468-76.

27. Bienz M, Clevers H. Linking colorectal cancer to Wnt signaling. Cell 2000;103:311-20.

28. Suzuki H, Watkins DN, Jair KW, et al. Epigenetic inactivation of SFRP genes allows constitutive WNT signaling in colorectal cancer. Nat Genet 2004;36:417-22.

29. Kwak B, Kim DU, Kim TO, et al. MicroRNA-552 links 
Wnt signaling to $\mathrm{p} 53$ tumor suppressor in colorectal cancer. Int J Oncol 2018;53:1800-8.

30. Reya T, Duncan AW, Ailles L, et al. A role for Wnt signalling in self-renewal of haematopoietic stem cells. Nature 2003;423:409-14.

31. Brack AS, Conboy MJ, Roy S, et al. Increased Wnt signaling during aging alters muscle stem cell fate and increases fibrosis. Science 2007;317:807-10.

32. Veltri A, Lang C, Lien W-H. Concise Review: Wnt Signaling Pathways in Skin Development and Epidermal Stem Cells. Stem Cells 2018;36:22-35.

33. Janda CY, Dang LT, You C, et al. Surrogate Wnt agonists that phenocopy canonical Wnt and beta-catenin signalling. Nature 2017;545:234.

34. Wang Y, Zhang X, Shao J, et al. Adiponectin regulates BMSC osteogenic differentiation and osteogenesis through the Wnt/ -catenin pathway. Sci Rep 2017;7:3652.

35. Maeda K, Kobayashi Y, Koide M, et al. The Regulation of Bone Metabolism and Disorders by Wnt Signaling. Int J Mol Sci 2019;20:5525.

36. Yan KS, Janda CY, Chang J, et al. Non-equivalence of Wnt and R-spondin ligands during Lgr5(+) intestinal stem-cell self-renewal. Nature 2017;545:238.

37. Martyn I, Kanno TY, Ruzo A, et al. Self-organization of a human organizer by combined Wnt and Nodal signalling. Nature 2018;558:132.

38. Zhang J, Cai H, Sun L, et al. LGR5, a novel functional glioma stem cell marker, promotes EMT by activating the Wnt/beta-catenin pathway and predicts poor survival of glioma patients. J Exp Clin Cancer Res 2018;37:225.

39. Tian E, Zhan FH, Walker R, et al. The role of the Wnt-signaling antagonist DKK1 in the development of osteolytic lesions in multiple myeloma. N Engl J Med 2003;349:2483-94.

40. Cosman F, Crittenden DB, Adachi JD, et al. Romosozumab Treatment in Postmenopausal Women with Osteoporosis. N Engl J Med 2016;375:1532-43.

41. Spranger S, Bao R, Gajewski TF. Melanoma-intrinsic betacatenin signalling prevents anti-tumour immunity. Nature 2015;523:231-5.

42. Liang J, Liang L, Ouyang K, et al. MALATI induces tongue cancer cells' EMT and inhibits apoptosis through Wnt/beta-catenin signaling pathway. J Oral Pathol Med 2017;46:98-105.

43. Xia L, Wu L, Bao J, et al. Circular RNA circ-CBFB promotes proliferation and inhibits apoptosis in chronic lymphocytic leukemia through regulating miR-607/ FZD3/Wnt/beta-catenin pathway. Biochem Biophys Res
Commun 2018;503:385-90.

44. Zhang J, Lai W, Li Q, et al. A novel oncolytic adenovirus targeting Wnt signaling effectively inhibits cancer-stem like cell growth via metastasis, apoptosis and autophagy in HCC models. Biochem Biophys Res Commun 2017;491:469-77.

45. Zheng R, Deng Q, Liu Y, et al. Curcumin Inhibits Gastric Carcinoma Cell Growth and Induces Apoptosis by Suppressing the Wnt/beta-Catenin Signaling Pathway. Med Sci Monit 2017;23:163-71.

46. Gao K, Shen Z, Yuan Y, et al. Simvastatin inhibits neural cell apoptosis and promotes locomotor recovery via activation of $\mathrm{Wnt} /$ beta-catenin signaling pathway after spinal cord injury. J Neurochem 2016;138:139-49.

47. Kong L-Y, Xue M, Zhang Q-C, et al. In vivo and in vitro effects of microRNA-27a on proliferation, migration and invasion of breast cancer cells through targeting of SFRP1 gene via Wnt/beta-catenin signaling pathway. Oncotarget 2017;8:15507-19.

48. Li N, Yang L, Sun Y, et al. MicroRNA-16 inhibits migration and invasion via regulation of the Wnt/ $\beta$-catenin signaling pathway in ovarian cancer. Oncol Lett 2019;17:2631-8.

49. Jiang Q, He M, Guan S, et al. MicroRNA-100 suppresses the migration and invasion of breast cancer cells by targeting FZD-8 and inhibiting Wnt/beta-catenin signaling pathway. Tumour Biol 2016;37:5001-11.

50. Liang T-S, Zheng Y-J, Wang J, et al. MicroRNA-506 inhibits tumor growth and metastasis in nasopharyngeal carcinoma through the inactivation of the Wnt/-catenin signaling pathway by down-regulating LHX2. J Exp Clin Cancer Res 2019;38:97.

51. Yu F, Lu Z, Huang K, et al. MicroRNA-17-5p-activated $\mathrm{Wnt} /$ beta-catenin pathway contributes to the progression of liver fibrosis. Oncotarget 2016;7:81-93.

52. Hu S, Mao G, Zhang Z, et al. MicroRNA-320c inhibits development of osteoarthritis through downregulation of canonical Wnt signaling pathway. Life Sci 2019;228:242-50.

53. Shi Z-Y, Deng J-X, Fu S, et al. Protective effect of autophagy in neural ischemia and hypoxia: Negative regulation of the Wnt/beta-catenin pathway. Int J Mol Med 2017;40:1699-708.

54. Su N, Wang P, Li Y. Role of Wnt/beta-catenin pathway in inducing autophagy and apoptosis in multiple myeloma cells. Oncol Lett 2016;12:4623-9.

55. Li X, Lu Q, Xie W, et al. Anti-tumor effects of triptolide on angiogenesis and cell apoptosis in osteosarcoma 
cells by inducing autophagy via repressing Wnt/betaCatenin signaling. Biochem Biophys Res Commun 2018;496:443-9.

56. Peng Y, Cao J, Yao X-Y, et al. TUSC3 induces autophagy in human non-small cell lung cancer cells through Wnt/ beta-catenin signaling. Oncotarget 2017;8:52960-74.

57. Visvader JE. Cells of origin in cancer. Nature 2011;469:314-22.

58. de Sousa e Melo F, Vermeulen L. Wnt Signaling in Cancer Stem Cell Biology. Cancers (Basel) 2016;8:60.

59. Veeman MT, Axelrod JD, Moon RT. A second canon: Functions and mechanisms of beta-catenin-independent wnt signaling. Dev Cell 2003;5:367-77.

60. Kuhl M, Sheldahl LC, Park M, et al. The Wnt/Ca2+ pathway - a new vertebrate $W$ nt signaling pathway takes shape. Trends Genet 2000;16:279-83.

Cite this article as: Xu JQ, Tang N, Zhang LF, Tan C, Su Y, George DM, He GX, Huang TL. A bibliometric analysis of Wnt signaling pathway: from the top-100 cited articles to emerging trends. Ann Transl Med 2021;9(13):1065. doi: 10.21037/atm-21174
61. Eyre R, Alferez DG, Santiago-Gomez A, et al. Microenvironmental IL1 beta promotes breast cancer metastatic colonisation in the bone via activation of $\mathrm{Wnt}$ signalling. Nat Commun 2019;10:5016.

62. Inoki K, Ouyang H, Zhu T, et al. TSC2 integrates Wnt and energy signals via a coordinated phosphorylation by AMPK and GSK3 to regulate cell growth. Cell 2006;126:955-68.

63. Rodda SJ, McMahon AP. Distinct roles for Hedgehog and canonical Wnt signaling in specification, differentiation and maintenance of osteoblast progenitors. Development 2006;133:3231-44.

64. Ahmad SS, Ahmad SS, Kohl S, et al. The Hundred Most Cited Articles in Bariatric Surgery. Obes Surg 2015;25:900-9. 


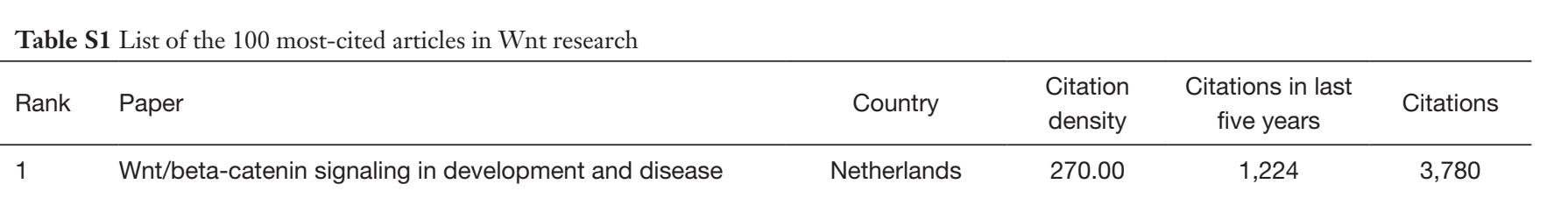

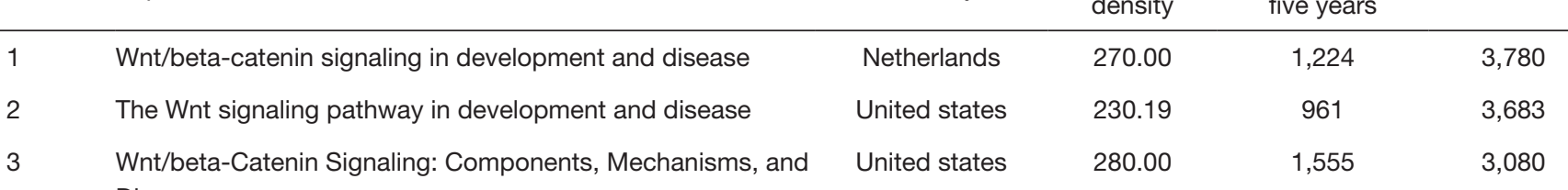

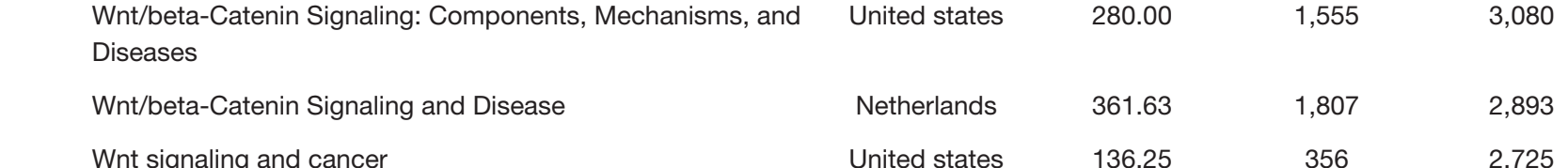

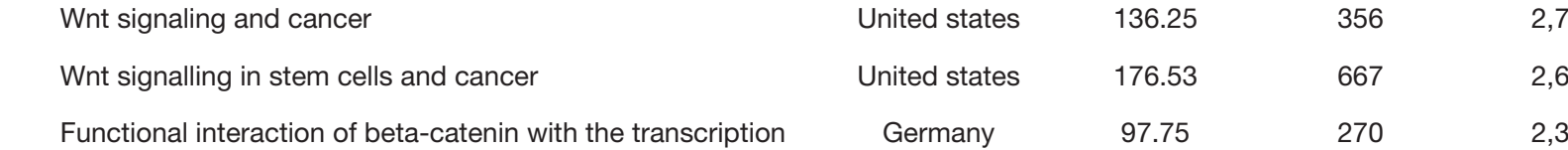
tactor LEF-1

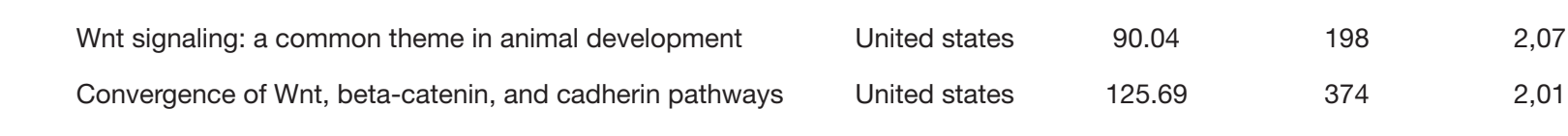

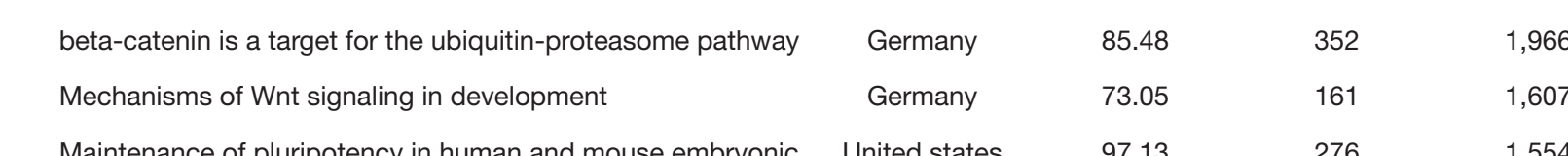

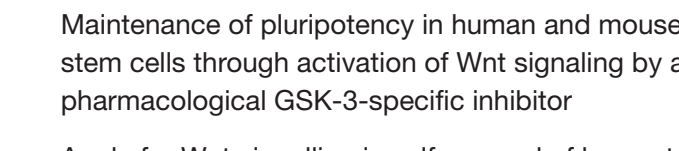

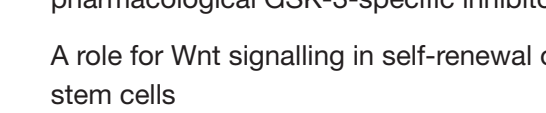

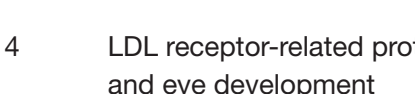

15 Whetrotins are lipic

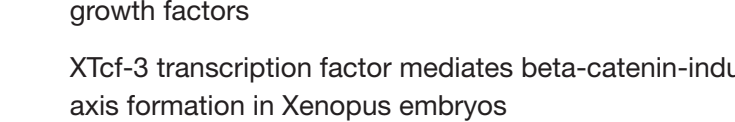

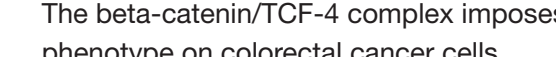

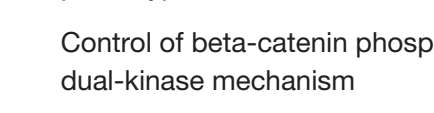

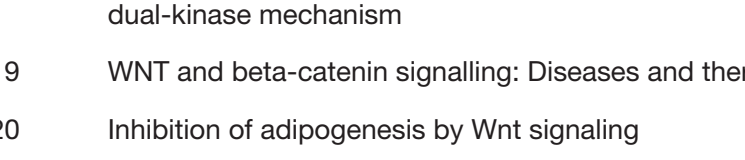

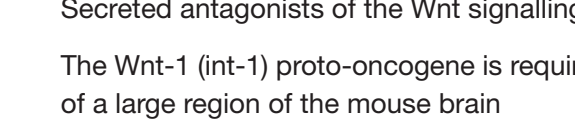

Unired states

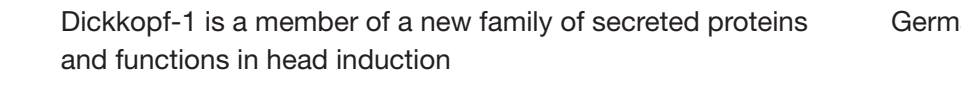

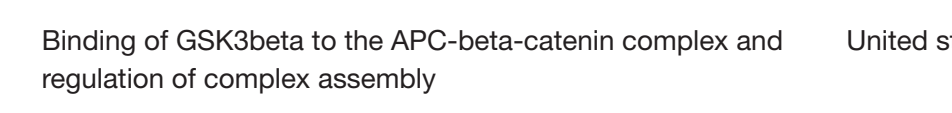

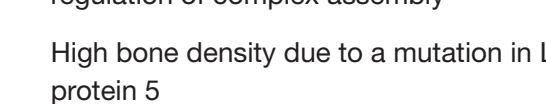

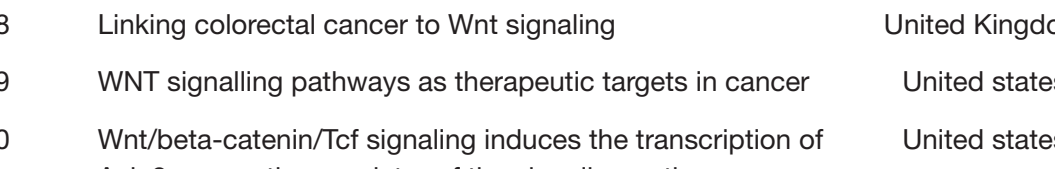

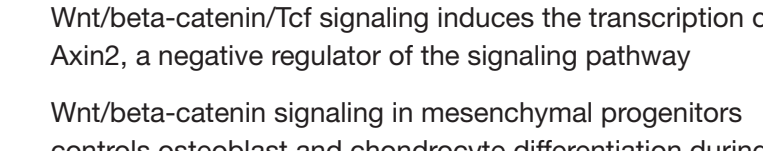

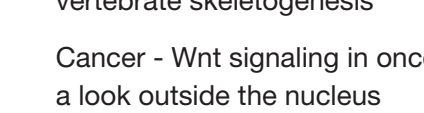

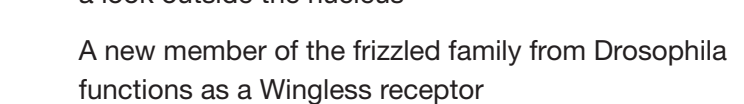

United stats

Whit signaling a

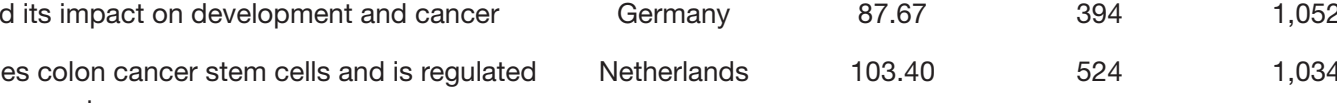

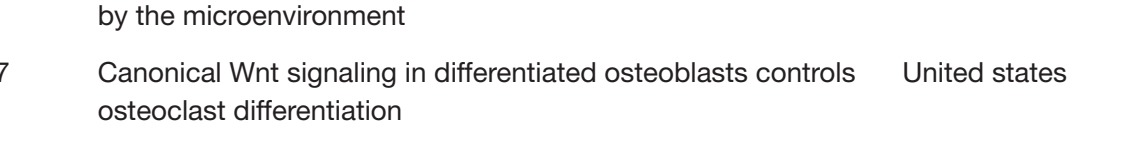

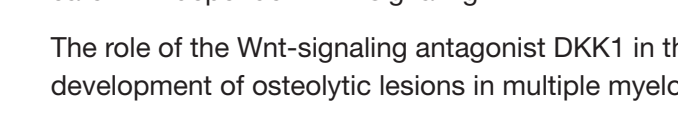

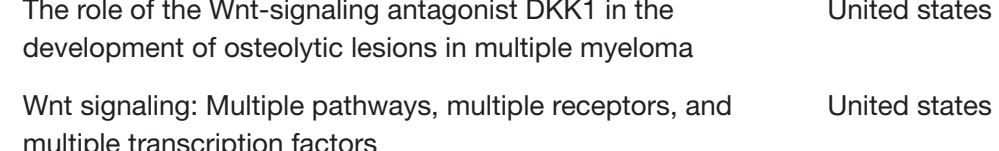

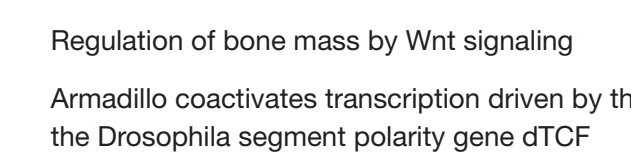

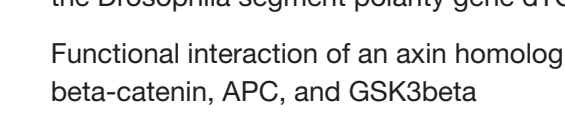

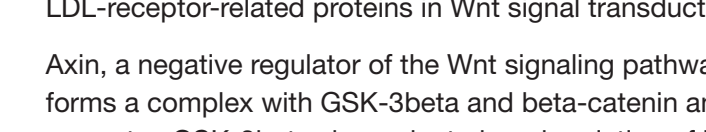

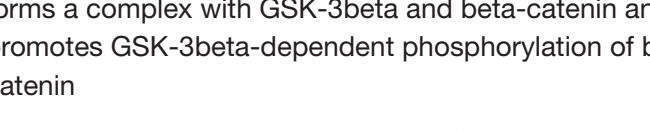

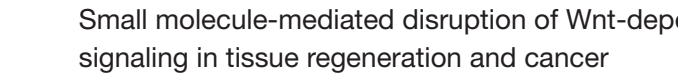

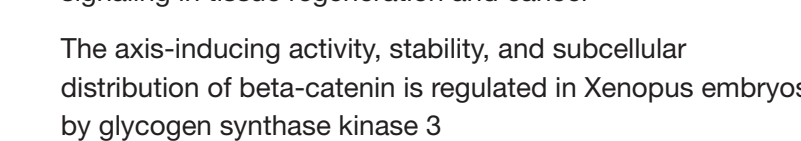

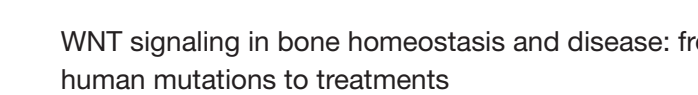

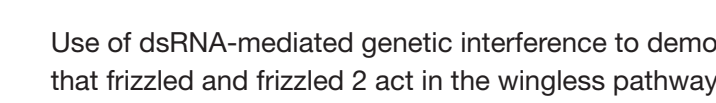

$51 \substack{\text { Sclerosit } \\ \text { sganang }}$

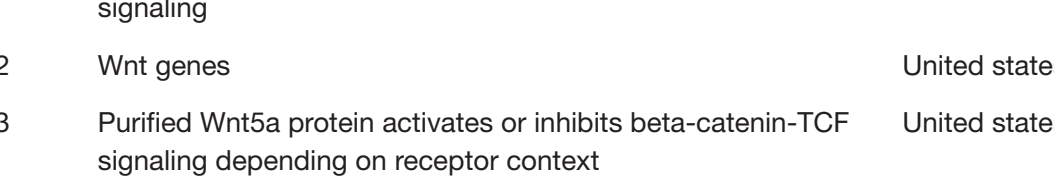

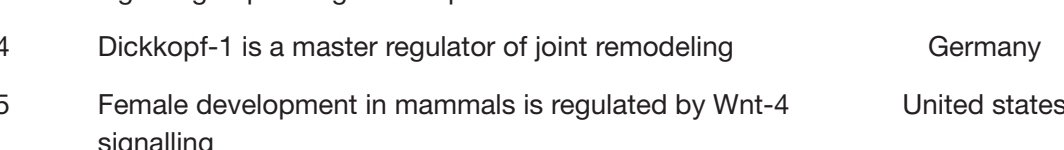

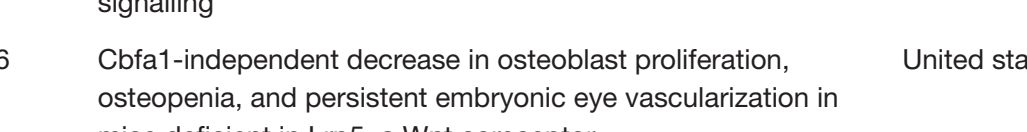

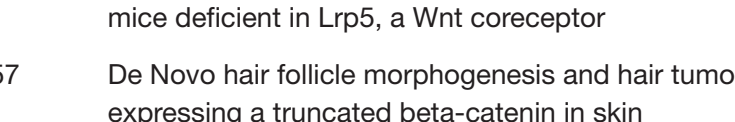

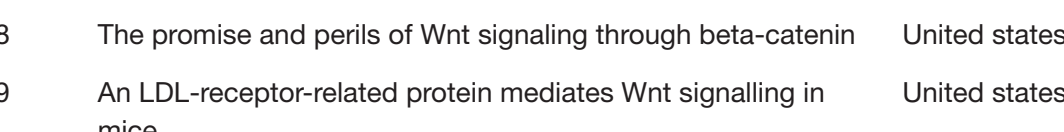

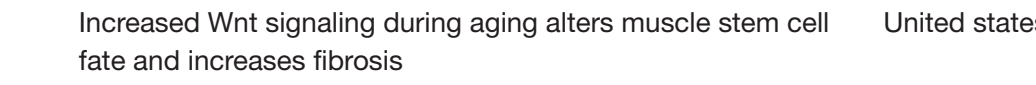

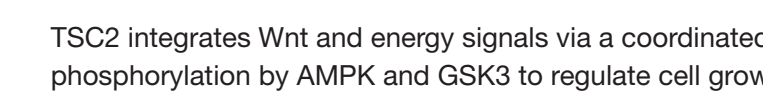

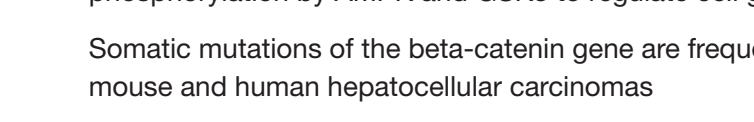

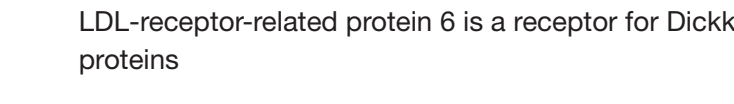

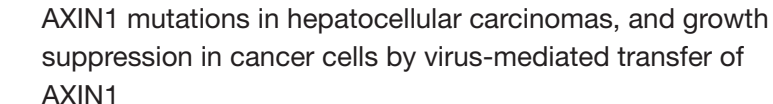

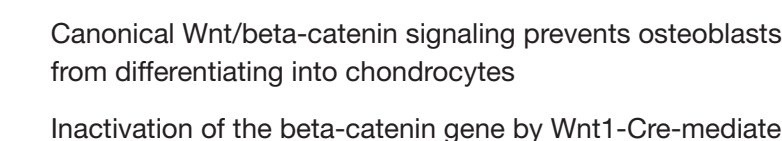

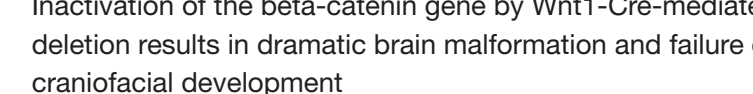

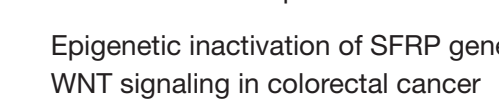

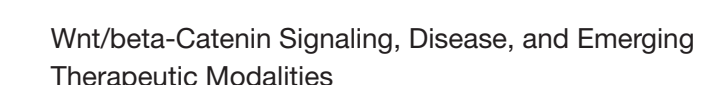

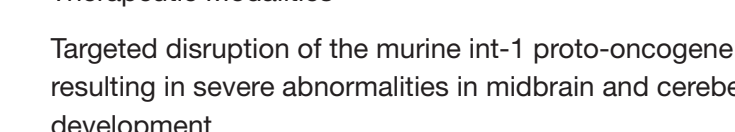

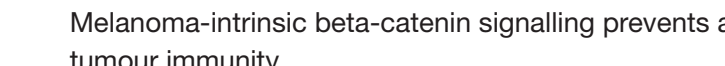

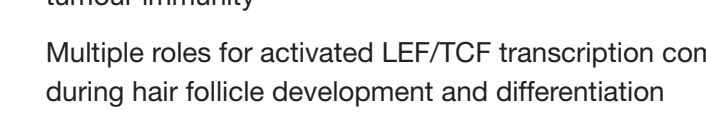

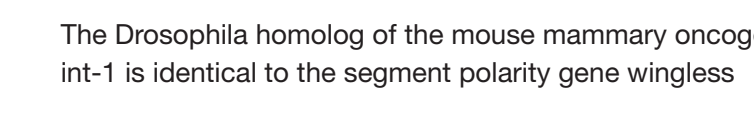

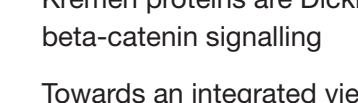

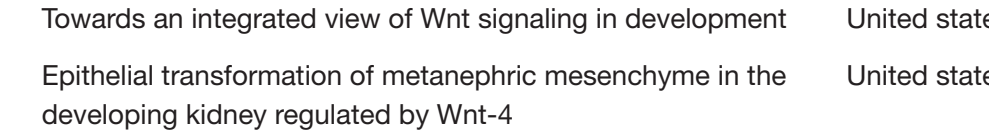

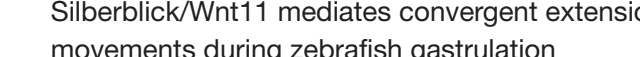

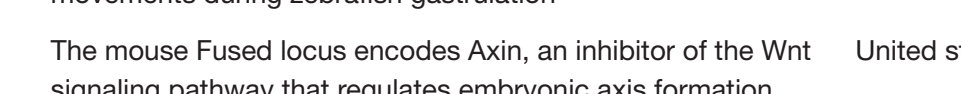

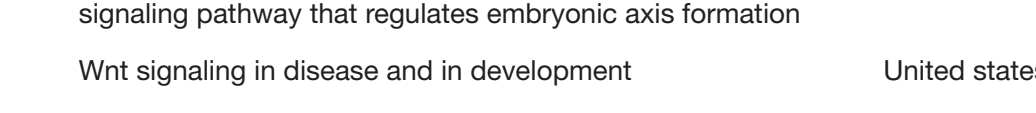

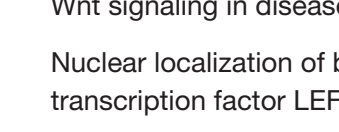

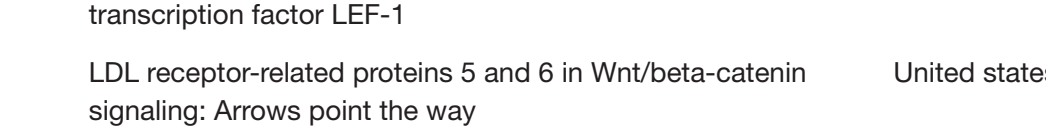

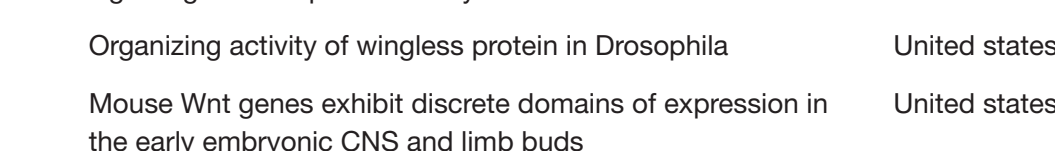

Canonical WN Signaing promotos ostood

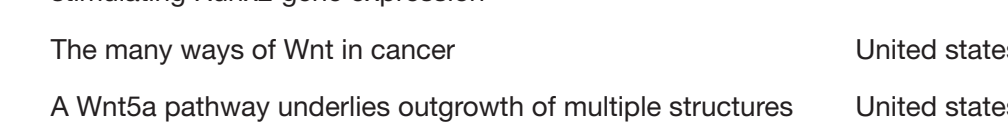

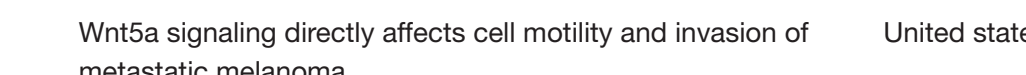

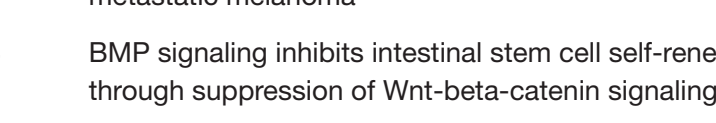

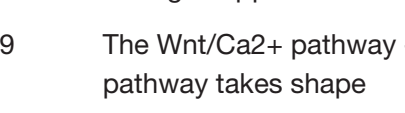

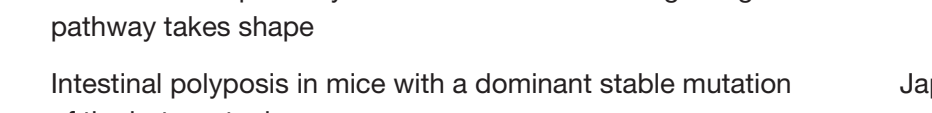

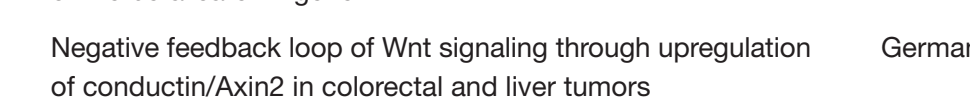

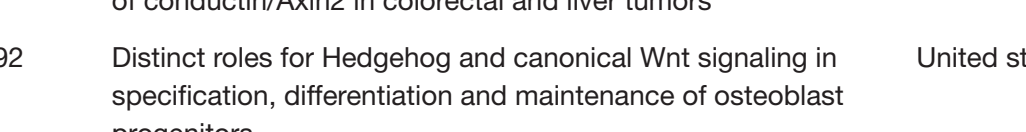

WNT Signalas are required tor the initiation of har tollicic

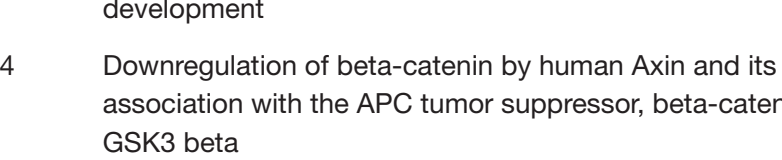

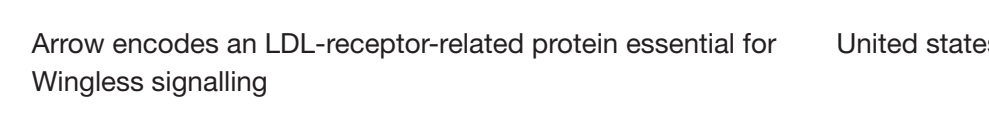

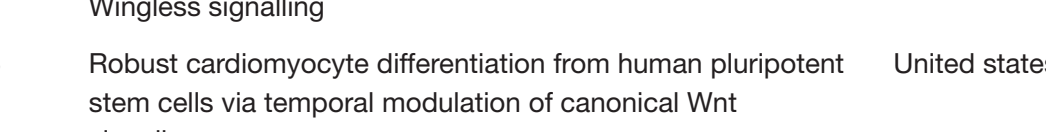

97. Function and biological roles of the Dickkopt family of

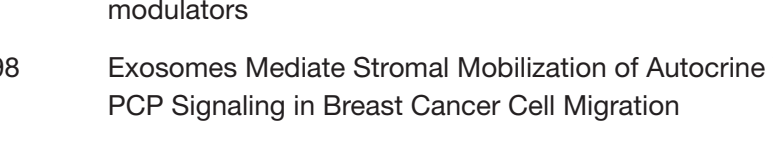

Canonical What signalas are essential tor homeossasis of the Nether

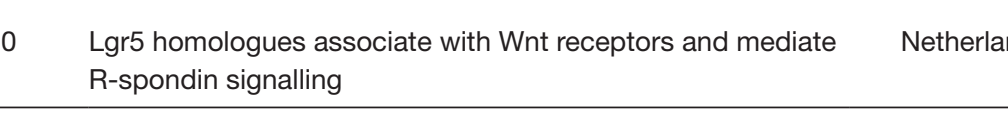


Table S2 Journal in which the top-cited 100 articles were published

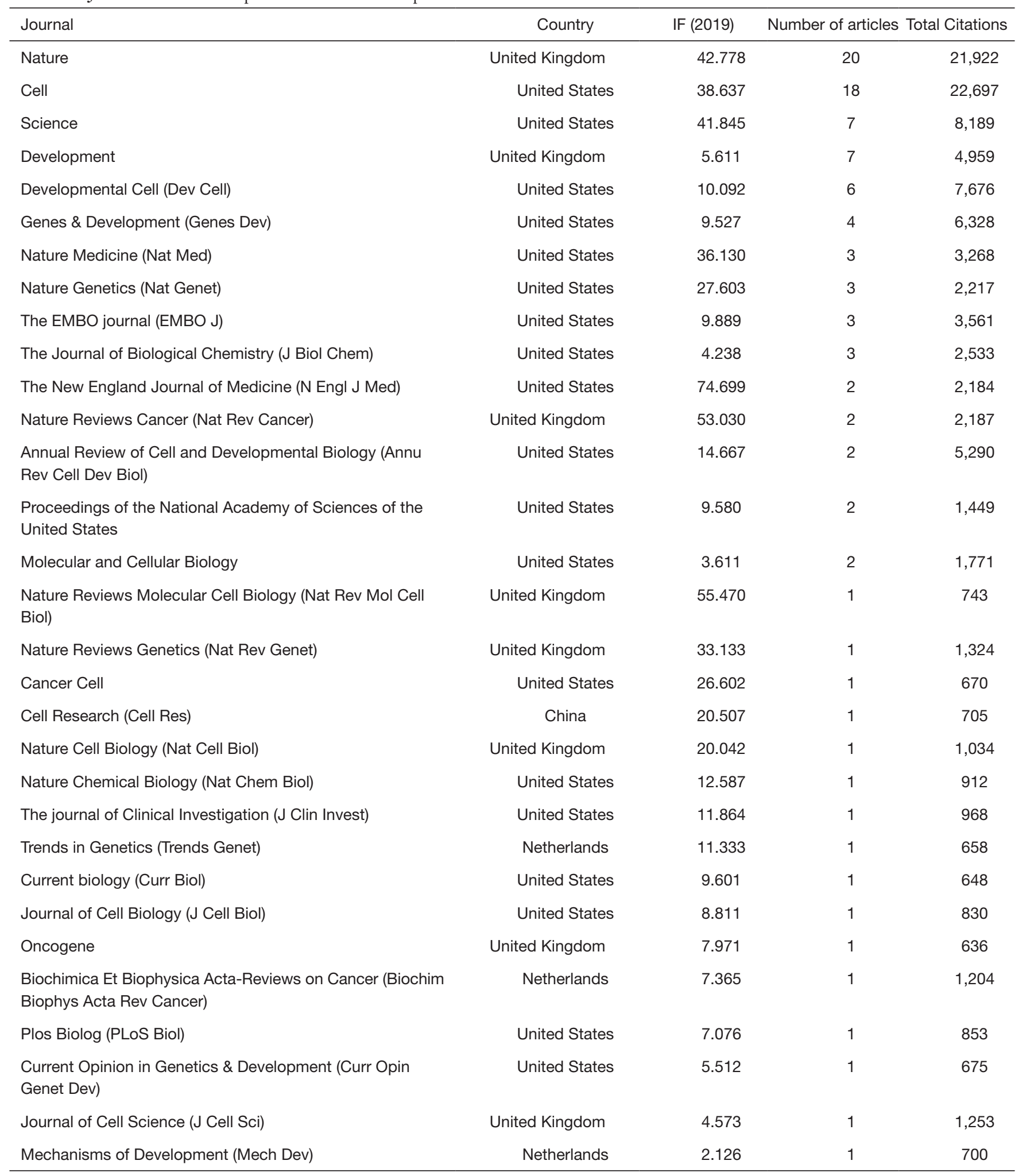


Table S3 Top 30 keywords ranked by weight/total link strength

\begin{tabular}{|c|c|c|c|c|c|}
\hline Keywords & cluster & Links & Weight/Total link strength & Occurrences & Average publication year \\
\hline Beta-catenin & 4 & 108 & 3,010 & 2,249 & 2015.6066 \\
\hline Proliferation & 4 & 100 & 1,669 & 856 & 2016.8452 \\
\hline Wnt signaling & 3 & 104 & 1,586 & 1,526 & 2015.844 \\
\hline Colorectal cancer & 1 & 89 & 1,067 & 759 & 2016.5346 \\
\hline Wnt/beta-catenin & 4 & 96 & 1,048 & 936 & 2016.7933 \\
\hline Metastasis & 1 & 85 & 1,011 & 531 & 2016.6844 \\
\hline Invasion & 4 & 68 & 926 & 392 & 2017 \\
\hline Breast cancer & 1 & 86 & 667 & 458 & 2016.1615 \\
\hline Differentiation & 2 & 90 & 663 & 454 & 2015.6971 \\
\hline Notch & 2 & 85 & 653 & 297 & 2015.3209 \\
\hline Epithelial-mesenchymal transition & 1 & 76 & 590 & 336 & 2017.1541 \\
\hline Hepatocellular carcinoma & 1 & 76 & 585 & 441 & 2016.355 \\
\hline Prognosis & 1 & 68 & 573 & 375 & 2016.6166 \\
\hline Wnt signaling pathway & 1 & 90 & 554 & 581 & 2016.7138 \\
\hline EMT & 1 & 80 & 543 & 285 & 2016.7979 \\
\hline Wnt/beta-catenin signaling & 3 & 79 & 470 & 473 & 2016.3511 \\
\hline Wnt/beta-catenin pathway & 4 & 74 & 437 & 442 & 2017.153 \\
\hline Osteoporosis & 3 & 56 & 430 & 369 & 2016.1181 \\
\hline Microrna & 1 & 93 & 418 & 297 & 2016.375 \\
\hline Colon cancer & 4 & 69 & 414 & 303 & 2015.9007 \\
\hline Osteoblast & 3 & 67 & 412 & 252 & 2015.6964 \\
\hline
\end{tabular}

(c) Annals of Translational Medicine. All rights reserved. 
Table S4 Top 30 keywords ranked by average publication year

\begin{tabular}{|c|c|c|c|c|c|}
\hline Keywords & cluster & Links & Weight/Total link strength & Occurrences & Average publication year \\
\hline Wnt/beta-catenin signaling pathway & 4 & 63 & 310 & 322 & 2017.2368 \\
\hline Epithelial-mesenchymal transition & 1 & 76 & 590 & 336 & 2017.1541 \\
\hline Wnt/beta-catenin pathway & 4 & 74 & 437 & 442 & 2017.153 \\
\hline Migration & 4 & 76 & 746 & 331 & 2017.1037 \\
\hline Invasion & 4 & 68 & 926 & 392 & 2017 \\
\hline Biomarker & 1 & 64 & 203 & 140 & 2016.9857 \\
\hline Autophagy & 3 & 71 & 314 & 170 & 2016.9458 \\
\hline Proliferation & 4 & 100 & 1,669 & 856 & 2016.8452 \\
\hline Glioma & 4 & 49 & 282 & 169 & 2016.8393 \\
\hline Cervical cancer & 1 & 51 & 179 & 113 & 2016.8036 \\
\hline EMT & 1 & 80 & 543 & 285 & 2016.7979 \\
\hline Wnt/beta-catenin & 4 & 96 & 1,048 & 936 & 2016.7933 \\
\hline Transcriptome & 2 & 49 & 101 & 125 & 2016.7903 \\
\hline Gastric cancer & 1 & 69 & 479 & 319 & 2016.7651 \\
\hline Osteogenesis & 3 & 59 & 257 & 197 & 2016.7409 \\
\hline Cell proliferation & 4 & 72 & 346 & 243 & 2016.6444 \\
\hline Prognosis & 1 & 68 & 573 & 375 & 2016.6166 \\
\hline Mirna & 1 & 74 & 209 & 183 & 2016.6111 \\
\hline Colorectal cancer & 1 & 89 & 1,067 & 759 & 2016.5346 \\
\hline Ovarian cancer & 1 & 64 & 253 & 159 & 2016.5063 \\
\hline Drug resistance & 1 & 62 & 173 & 100 & 2016.5 \\
\hline
\end{tabular}

